\title{
Trends in quality of screening colonoscopy in Austria
}

Authors

Institutions
Elisabeth Waldmann ${ }^{1,2}$, Irina Gess $\left.\right|^{1,2}$, Daniela Sallinger ${ }^{1,2}$, Philip Jeschek ${ }^{1,2}$, Martha Britto-Arias ${ }^{1,2}$, Georg Heinze $^{3}$, Elisabeth Fasching ${ }^{4}$, Werner Weiss ${ }^{2}$, Michael Gschwantler ${ }^{2}$, Michael Trauner ${ }^{1,2}$, Monika Ferlitsch ${ }^{1,2}$

Institutions are listed at end of article. submitted: 14. June 2015 accepted after revision: 30. June 2016

\section{Bibliography}

Dol http://dx.doi.org/

10.1055/s-0042-113185

Published online: 30.8.2016

Endoscopy 2016; 48: 11021109

(c) Georg Thieme Verlag KG Stuttgart · New York ISSN 0013-726X

\section{Corresponding author}

Monika Ferlitsch, MD

Division of Gastroenterology and Hepatology

Department of Internal

Medicine III

Medical University of Vienna

Waehringer Guertel 18-20

A-1090 Vienna

Austria

Fax: +43-1-4040047350

monika.ferlitsch@meduniwien. ac.at
Background and study aim: Screening colonoscopy only effectively prevents colorectal cancer if performed with high quality. The aim of this study was to analyze the detection rates of premalignant colorectal lesions in screening colonoscopies performed within a nationwide quality control program for screening colonoscopy in Austria.

Methods: Data from electronic records of the screening program from its implementation in 2007 until December 2014 were analyzed in order to calculate detection rates for adenomas, advanced adenomas, polyps, and proximal lesions, and rates of cecal intubation, sedation, complications, and adequate bowel preparation. Results were evaluated to identify trends and changes in quality parameters over the 8-year study period. Results: During the study period, 301 endoscopists provided data from 159246 screening colonoscopies. Mean age of screened individuals was 61.1 years, and $49.1 \%$ were women. Significant increases over time were found for age- and sex-adjusted adenoma detection rates (ADRs), which increased from a mean of $22.2 \%$ (SD 10.7\%) in $2007 / 2008$ to $24.2 \%$ (SD $11.6 \%$ ) in $2013 / 2014$.

\section{Introduction}

Screening colonoscopy is recognized as the gold standard modality for the prevention of colorectal cancer (CRC) [1,2]. In 2013, seven European Union (EU) states used either screening colonoscopy alone or in combination with fecal occult blood testing as a primary screening tool [3]. As screening colonoscopy is an invasive procedure on a healthy screening population, the benefit must be as high as possible and the risks (e.g. bleeding, perforation) must be reduced to a minimum. In recent years, the quality of endoscopic equipment, bowel preparation, and skill of the individual endoscopist has improved considerably, and guidelines have required increasingly higher
On average, each endoscopist increased their individual ADR by +1.5 percentage points per 2 -year period (95\% confidence interval [CI] 0.9-2.2 percentage points; $P<0.01)$. Similarly, detection rates for proximal lesions rose from $15.8 \%$ (SD 9.8\%) to $21.7 \%$ (SD $13.3 \%+2.5$ percentage points per 2year period, $95 \%$ CI $1.9-3.1$ percentage points; $P<0.01$ ). ADR in men increased from $27.6 \%$ in 2007/2008 (SD 11.1\%) to $29.2 \%$ in 2013/2014 (SD 12.7\%; $P<0.01$ ); ADR in women increased from $14.2 \%$ (SD $7.1 \%$ ) in $2007 / 2008$ to $19.0 \%$ (SD $10.5 \%)$ in $2013 / 2014(P<0.01)$. Advanced adenoma detection rates decreased during the study period, from $11.4 \%$ (SD 9.0\%) in 2007/2008 to $7.6 \%$ (SD 5.4\%) in 2013/2014 $(P=0.06)$ in men, and from $5.5 \%$ (SD 5.3\%) in $2007 / 2008$ to $4.0 \%$ (SD $4.1 \%)$ in $2013 / 2014$ in women $(P=0.21)$.

Conclusions: This study showed an improvement in the quality of screening colonoscopies performed within a quality assurance program in Austria between 2007 and 2014. Although, overall ADR increased significantly during the study period, there was a decrease in the rate of advanced adenoma detection.

quality standards [4-6]. The current EU guideline emphasizes that "infrequent high quality examinations are probably more effective in prevention of colorectal cancer than are frequent low quality examinations" [7]. The outstanding benefit of quality assurance programs with constant audit and feedback on both improving the procedure as well as setting new standards has been demonstrated in several landmark publications [8-10]. However, in Europe such programs are scarce. Austria implemented screening colonoscopy in 2005. Due to the lack of obligatory quality control, a quality assurance program was implemented in 2007. The aim of this current study was to analyze trends in detection rates of premalignant colorectal lesions in screening colonoscopies performed 
within the nationwide quality assurance program for screening colonoscopy in Austria.

\section{Methods}

Data from electronic records of the quality assurance program for screening colonoscopy, from its implementation in 2007 until December 2014, were analyzed in order to calculate detection rates for adenomas, advanced adenomas, polyps, and proximal lesions, and rates of cecal intubation, sedation, complications, and adequate bowel preparation. Results were evaluated to identify trends and changes in quality parameters over the 8-year study period. The study period was divided into four 2-year blocks and detection rates were computed within these blocks. Only those participants who had performed at least 20 colonoscopies during the study blocks were included in the study.

\section{The screening program}

In Austria, publicly funded opportunistic screening colonoscopy was implemented in 2005 as a primary CRC screening method for the average-risk population starting at the age of 50 years for both men and women. Because of the lack of obligatory quality assurance for screening colonoscopy, the Austrian Society of Gastroenterology and Hepatology in cooperation with the Austrian Federation of the Statutory Insurance Institutions and the Austrian Cancer Aid founded, in 2007, a national project for quality assurance in screening colonoscopy, the "Certificate of Quality for Screening Colonoscopy."

Minimum quality requirements for participation in the screening program include proof of performing at least 200 supervised colonoscopies and 50 supervised polypectomies, as well as an ongoing rate of 100 colonoscopies and 10 polypectomies per year of participation, photographic documentation of the cecum in each screened individual, and annual hygiene checks of the endoscopic equipment [11 - 17]. Every internist, gastroenterologist, or surgeon who meets these criteria, can apply for the certificate; nurses do not perform endoscopy in Austria. Participation in the quality assurance program is on a voluntary basis. The certificate of the quality assurance program is issued for a period of 2 years, after which it must be renewed in order for the operator to continue performing screening colonoscopies within the program.

Data on patient characteristics (age, sex) and the following colonoscopy report details are transmitted electronically via a standardized report form to the database of the quality assurance program: number, size, location and histology of the lesion detected; polypectomy technique; complications; recommended surveillance interval. If more than one lesion is detected, details of the size, shape, histology, location, and polypectomy technique for the most advanced lesion only are documented. The electronic reporting form is adapted continually according to ongoing progress in scientific research, for example introduction of the terms "traditional" and "sessile serrated adenoma," assessment of bowel preparation (excellent, good, fair, poor, poor only in the rightsided colon, not sufficient; based on the Aronchick scale). Screening data can only be transmitted and used if the screened individuals have provided written informed consent for data transmission, and the use of their data for quality assurance and scientific purposes. The ethics committee of the Medical University of Vienna and the Data Protection commission approved the "Certi- ficate of Quality for Screening Colonoscopy" (DVR number 0504211 from 17.10.2007).

\section{Definitions}

Advanced adenomas are defined as adenomas that are at least $10 \mathrm{~mm}$ in size or have high grade dysplasia, or villous or tubulovillous histology, or any combination thereof. Adenoma detection rate (ADR) is defined as the number of colonoscopies with at least one adenoma detected divided by the overall number of colonoscopies performed by respective endoscopists. This definition also applies correspondingly to advanced adenoma detection rate (AADR), polyp detection rate (PDR), and proximal lesion detection rate (PLDR). Proximal lesion is defined as a lesion located proximally to the sigmoid colon.

\section{Quality of data entry, audit, and feedback}

Every year three randomly selected colonoscopy reports within the database are checked for data accuracy for each participating endoscopist in order to verify the accuracy of data entry. The endoscopist presents the original colonoscopy report, including all data assessed within the electronically submitted colonoscopy report and including the statement of the reporting pathologist as well as photographic documentation of the cecum. If one or more entries are incorrect (missing data or incorrect data), the participating endoscopist is asked to submit data on another five patients randomly selected from the database; if these data are also incorrect, the endoscopist is excluded from the quality assurance program. In exchange for data transmission, participants receive benchmark reports twice a year containing detailed information on their personal performance compared with the anonymized performance of other participating endoscopists, as well as with the performance of each Austrian federal state.

\section{Hygiene control}

As hygiene controls for colonoscopes are mandatory in hospitals, only hygiene inspections of colonoscopes used in private practices are required within the quality assurance project. A germfree sample of the working channel, and the air and water channels of the colonoscope, as well as of the rinsing fluid from the endoscope washing machine must be provided annually. Test results have been assessed electronically since 2010 .

\section{Statistical analysis}

The detection rates were adjusted for age using the indirect method, and using the age distribution of all individuals who underwent colonoscopies between 2007 and 2014 as the reference population. Cecal intubation rates (CIR), and rates of sedation, complications, and excellent or good bowel preparation were similarly adjusted. The adjusted rates were then analyzed for time trends, and for differences between private practices and endoscopy units of hospitals or outpatient clinics, using linear mixed models, including fixed effects for period and setting, and random effects for period and endoscopist. Pearson correlation coefficients were computed between adjusted complication rates, adjusted proximal lesion detection rates, and adjusted ADRs for the period 2013/2014.

The SAS System V9.4 (2014 SAS Institute Inc., Cary, North Carolina, USA) was used for statistical analysis, and the software package R (R Core Team, 2014, Vienna, Austria) was used for statistical graphics. 


\section{Results}

$\nabla$

Between January 2007 and December 2014, 301 endoscopists, who were eligible to be included in the current study, participated in the screening program and provided data on a total of 159 246 screening colonoscopies (2007 $n=642 ; 2008 n=13510$; $2009 n=18$ 459; $2010 \mathrm{n}=20$ 954; $2011 \mathrm{n}=21$ 769; $2012 \mathrm{n}=25$ 535; $2013 n=29342 ; 2014 n=29$ 035). Of the screenees, $49.1 \%$ $(\mathrm{n}=78270)$ were women and $50.9 \%(\mathrm{n}=80$ 976) were men. The mean age for both men and women was 61.1 years (SD 9.2).

Approximately $67 \%$ of the participating endoscopists were internists (gastroenterologists and nongastroenterologists) and 33\% were surgeons.

The cecum was reached in $96.2 \%$ ( $n=153191$, unadjusted rate). Reasons for incomplete colonoscopy $(n=6055)$ were pain in $30.1 \%(n=1821)$, poor bowel preparation in $22.3 \%(n=1350)$, stenosis in $11.8 \%(n=715)$, complications in $1.8 \%(n=111)$, and others in $34.0 \%(n=2058)$. Sedation was used in $87.2 \%$ of procedures $(n=138863)$.

\section{Quality parameters and trends}

Detection rates

At least one polyp was found in $38.1 \%$ of colonoscopies $(n=$ $60597)$, at least one adenoma was detected in $21.6 \%(n=34365)$, and at least one advanced adenoma was detected in $6.3 \%(\mathrm{n}=$ $10094)$. The polypectomy rate was $95.5 \%(n=57890)$, and $97.3 \%(n=56322)$ of the polyps were retrieved for pathological examination.

Significant time trends were found for ADRs, which increased by +1.5 percentage points per 2-year period for an average endoscopist (95\% confidence interval [95\%CI] 0.9-2.2 percentage points; $P<0.01$ ). Overall, the mean ADR was $22.2 \%$ (SD $10.7 \%$, data from $n=106$ participating endoscopists) in 2007/2008 and $24.2 \%$ (SD $11.6 \%, \mathrm{n}=226$ ) in $2013 / 2014$.

ADR in men increased from 27.6\% (SD 11.1\%) in 2007/2008 to $29.2 \%$ (SD 12.7\%) in 2013/2014 (average increase per 2-year period +1.6 percentage points; $95 \% \mathrm{CI} 0.8-2.4$ percentage points; $P<$ 0.01 ). In women, the ADR increased from $14.2 \%$ (SD 7.1\%) in $2007 / 2008$ to $19.0 \%$ (SD 10.5\%) in $2013 / 2014$ (average increase

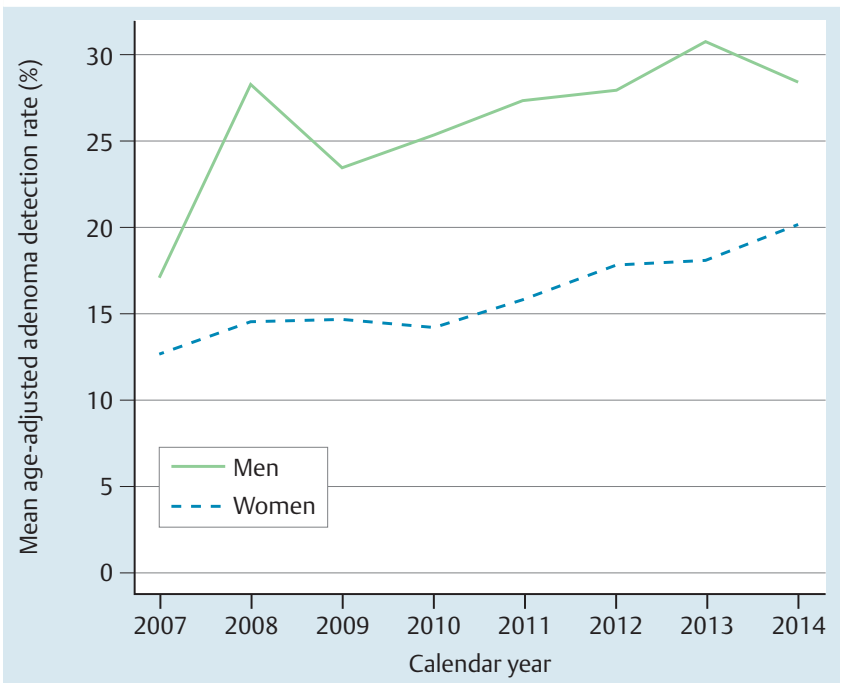

Fig.1 Age-adjusted adenoma detection rates for men and women per endoscopist in 2007/2008, 2009/2010, 2011/2012, and 2013/2014. per 2-year period +1.9 percentage points; $95 \% \mathrm{CI} 1.3-2.4$ percentage points; $P<0.01$ ).

Interestingly, the AADR decreased during the same periods. The AADR in men was $11.4 \%$ (SD 9.0\%) in 2007/2008 and 7.6\% (SD $5.4 \%$ ) in 2013/2014 (average decrease per 2-year period-0.4 percentage points; $95 \% \mathrm{CI}-0.9$ to +0.1 percentage points; $P=$ 0.06 ). The AADR in women decreased from $5.5 \%$ (SD $5.3 \%$ ) in $2007 / 2008$ to $4.0 \%$ (SD 4.1\%) in 2013/2014 (average decrease per period -0.3 percentage points; $95 \% \mathrm{CI}-1.6$ to +0.3 percentage points; $P=0.21$ ).

PDRs increased from $36.7 \%$ (SD $15.4 \%$ ) in $2007 / 2008$ to $42.0 \%$ (SD $17.3 \%)$ in $2013 / 2014$ (+2.9 percentage points per 2-year period; $95 \%$ CI $2.0-3.8$ percentage points; $P<0.01)$. PLDRs increased from $15.8 \%$ (SD $9.8 \%$ ) to $21.7 \%$ (SD $13.3 \% ;+2.5$ percentage points per 2-year period; $95 \%$ CI $1.9-3.1$ percentage points; $P<0.01)$. CIRs increased from $94.2 \%$ (SD $6.2 \%$ ) to $97.0 \%$ ( $4.8 \%$; +1.1 percentage points per 2-year period; $95 \% \mathrm{CI} 0.8-1.4$ percentage points; $P<$ 0.01). Sedation rates increased from $85.4 \%$ (SD 21.0\%) to $89.1 \%$ (SD $18.4 \% ;+1.8$ percentage points per 2 -year period; $95 \% \mathrm{Cl}$ $1.2-2.4$ percentage points; $P<0.01$ ).

$\bullet$ Fig.1, $\odot$ Fig.2, $\odot$ Fig. 3 and $\odot$ Fig.4 show the annual sex-specific age-adjusted ADRs, AADRs, PLDRs, and CIRs for all participating endoscopists over the years $2007-2014$.

\section{Bowel cleansing quality}

Adjusted rates of excellent or good quality of bowel cleansing were on average $45.9 \%$ (SD $49.0 \%$, number of participants who provided data on bowel preparation $=8$ ) in $2009 / 2010,78.1 \%$ (SD 30.9\%, $\mathrm{n}=150$ ) in 2011/2013, and 83.9\% (SD 13.5\%, $\mathrm{n}=226$ ) in $2014(+6.7$ percentage points per period; $95 \% \mathrm{CI}+2.5-+10.9$ percentage points; $P=0.02$ ).

Private practice vs. hospitals and outpatient clinics The age- and sex-adjusted detection rates of hospitals and outpatient clinics compared with private practices during the periods $2007 / 2008,2009 / 2010,2011 / 2012$, and 2013/14 are shown in - Table1. Averaged over all periods, hospitals and outpatient clinics exhibited higher PDRs (+3.3 percentage points; $95 \% \mathrm{CI}$ $0.2-6.5$ percentage points; $P=0.04)$ and sedation rates $(+4.0$ per-

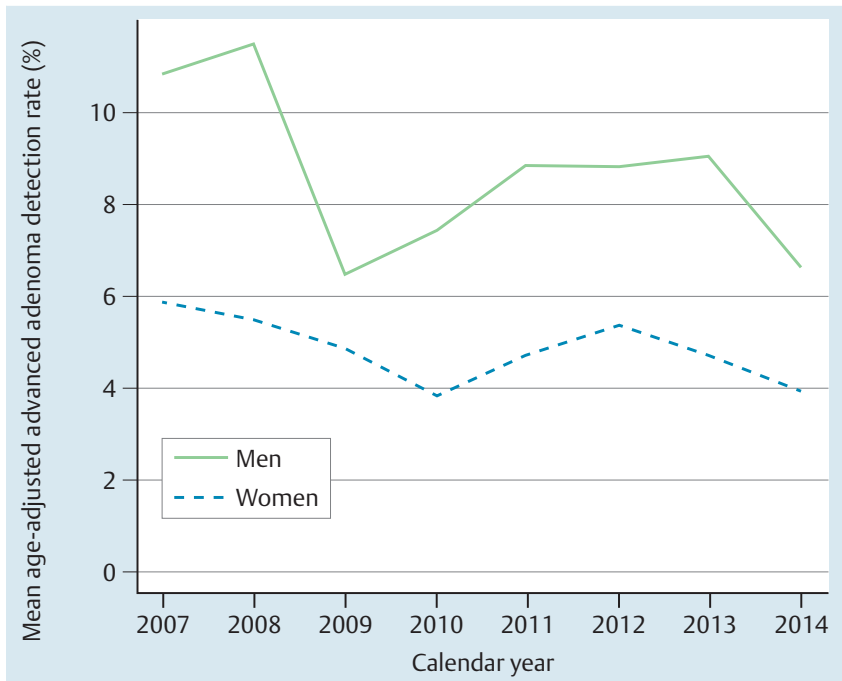

Fig.2 Age-adjusted advanced adenoma detection rates per endoscopist formen and women in 2007/2008, 2009/2010, 2011/2012, and 2013/2014. 


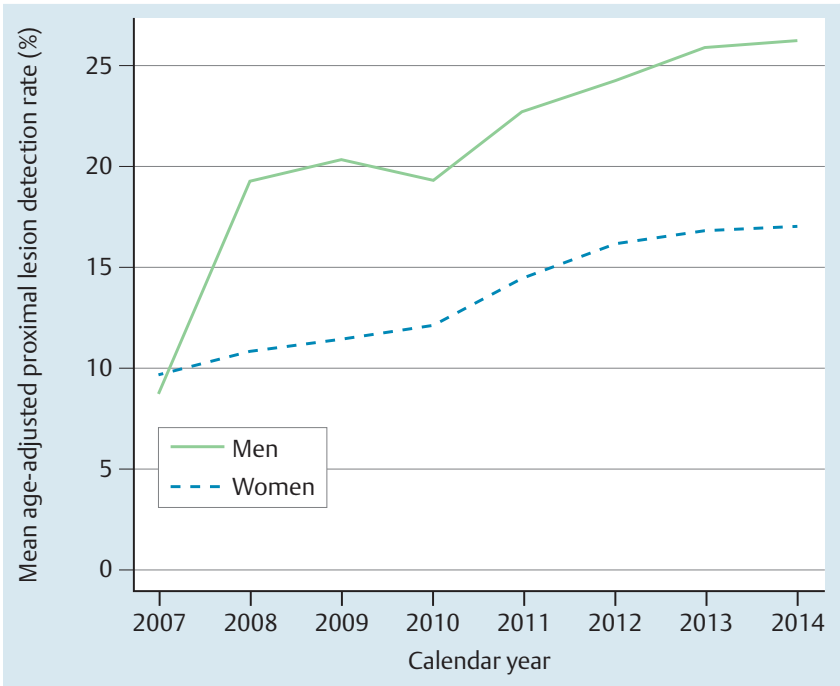

Fig.3 Age-adjusted proximal lesion detection rates per endoscopist for men and women in 2007/2008, 2009/2010, 2011/2012, and 2013/2014.

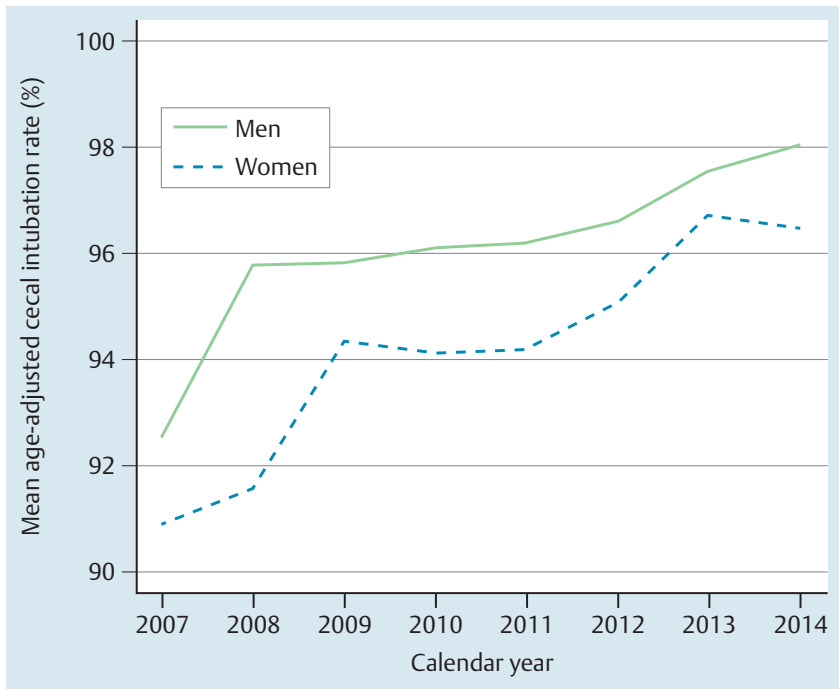

Fig.4 Age-adjusted cecal intubation rates per endoscopist for men and women in 2007/2008, 2009/2010, 2011/2012, and 2013/2014.

Table 1 Trends in age- and sex-adjusted rates.

\begin{tabular}{|c|c|c|c|c|}
\hline & \multicolumn{4}{|l|}{ Period } \\
\hline & $2007 / 2008$ & $2009 / 2010$ & $2011 / 2012$ & $2013 / 2014$ \\
\hline $\begin{array}{l}\text { Number or participants with }>20 \text { colonoscopies } \\
\text { per period, } n\end{array}$ & 106 & 178 & 202 & 226 \\
\hline Private practices & 71 & 113 & 154 & 174 \\
\hline Hospitals/outpatient clinics & 35 & 65 & 48 & 52 \\
\hline$A D R$, mean (SD), \% & $22.2(10.7)$ & $19.2(8.3)$ & $21.9(9.5)$ & $24.2(11.6)$ \\
\hline Private practices & $21.2(9.5)$ & $18.4(8.3)$ & $20.6(9.5)$ & $23.7(12.1)$ \\
\hline Hospitals/outpatient clinics & $24.3(12.7)$ & $20.5(8.2)$ & $26.1(8.3)$ & $26.0(9.4)$ \\
\hline AADR, mean (SD), \% & $9.1(8.3)$ & $5.6(4.0)$ & $7.0(5.2)$ & $6.0(4.9)$ \\
\hline Private practices & $9.0(7.5)$ & $5.5(4.0)$ & $6.6(5.0)$ & $6.1(5.1)$ \\
\hline Hospitals/outpatient clinics & $9.4(10)$ & $5.6(4.0)$ & $8.2(5.6)$ & $5.9(4.1)$ \\
\hline PDR, mean (SD), \% & $36.7(15.4)$ & $34.8(15.3)$ & $40.6(14.8)$ & $42.0(17.3)$ \\
\hline Private practices & $35.6(14.1)$ & $34.4(15.9)$ & $39.2(15.1)$ & $41.6(18.2)$ \\
\hline Hospitals/outpatient clinics & $38.9(17.7)$ & $35.4(14.4)$ & $45.3(12.8)$ & $43.6(13.9)$ \\
\hline PLDR, mean (SD), \% & $15.8(9.8)$ & $15.3(8.8)$ & $19.6(10.6)$ & $21.7(13.3)$ \\
\hline Private practices & $15.1(9.9)$ & $14.8(8.9)$ & $18.4(10.6)$ & $21.4(14.1)$ \\
\hline Hospitals/outpatient clinics & $17.3(9.6)$ & $16.2(8.6)$ & $23.3(9.6)$ & $22.8(10.4)$ \\
\hline CIR, mean (SD), \% & $94.2(6.2)$ & $95.1(5.8)$ & $95.5(5.5)$ & $97.0(4.8)$ \\
\hline Private practices & $93.4(6.9)$ & $94.1(6.8)$ & $95.0(6.0)$ & $96.7(5.2)$ \\
\hline Hospitals/outpatient clinics & $96.1(3.7)$ & $96.8(2.8)$ & $97.1(3.1)$ & $97.7(3.1)$ \\
\hline Sedation rate, mean (SD), \% & $85.4(21.0)$ & $85.6(19.5)$ & $87.7(17.4)$ & $89.1(18.4)$ \\
\hline Private practices & $84.6(23.1)$ & $84.2(21.7)$ & $86.6(18.9)$ & $89.9(17.7)$ \\
\hline Hospitals/outpatient clinics & $87.1(16)$ & $87.9(14.8)$ & $91.1(10.9)$ & $86.4(20.6)$ \\
\hline Complications per 10000 colonoscopies, mean (SD), n & $43.2(113.5)$ & $31.8(81.0)$ & $34.8(110.5)$ & $14.6(36.6)$ \\
\hline Private practices & $49.1(128.6)$ & $30.1(86.4)$ & $28.6(92.7)$ & $13.7(39)$ \\
\hline Hospitals/outpatient clinics & $31.2(74.3)$ & $34.7(71)$ & $92.4(145.1)$ & $17.6(27.2)$ \\
\hline $\begin{array}{l}\text { Rate of excellent or good quality of bowel } \\
\text { cleansing*, } \\
\text { mean (SD), \% }\end{array}$ & N/A & $45.9(49.0)$ & $78.1(30.9)$ & $83.9(13.5)$ \\
\hline Private practices & $N / A$ & $45.9(49)$ & $82.9(25.8)$ & $85.2(12.6)$ \\
\hline Hospitals/outpatient clinics & $\mathrm{N} / \mathrm{A}$ & $\mathrm{N} / \mathrm{A}$ & $61.1(40.5)$ & 79.5 (15.7) \\
\hline
\end{tabular}

$A D R$, adenoma detection rate; AADR, advanced adenoma detection rate; CIR, cecal intubation rate; PDR, polyp detection rate; PLDR, proximal lesion detection rate; N/A, not applicable.

* Number of participants who provided data on bowel preparation for the respective year blocks: overall $n=0, n=8, n=150, n=226$; private practice $n=1, n=8, n=117, n=174$; hospital/outpatient clinics $n=0, n=0, n=33, n=52$. 
centage points; $95 \% \mathrm{CI} 1.0-6.9$ percentage points; $P=0.01$ ) compared with private practices. In private practices, the quality of bowel cleansing was excellent or good more often than in hospitals and outpatient clinics (+6.7 percentage points, 95\%CI $2.5-$ 10.9 percentage points; $P<0.01)$. CIRs were higher for hospitals and outpatient clinics (+1.3 percentage points; 95\%CI $0.2-2.4$ percentage points). No significant differences between private practices and hospitals/outpatient clinics were found for ADRs $(P=0.62)$, AADRs $(P=0.96)$, and PLDRs $(P=0.22)$.

While in $2007 / 200847.9 \%$ (34 of 71) of private practice-based endoscopists fell below the quality standard of ADR (20\%), this figure decreased to $37.4 \%$ (65 of 174 ) in $2013 / 2014(P<0.01$ ). In $2007 / 2008$, the CIR was lower than $90 \%$ for $18.3 \%$ of the private practice-based endoscopists, whereas in 2013/2014, only $7.5 \%$ of these endoscopists fell below this limit $(P=0.01)$. Similar trends, though not significant, were observed for hospitals and outpatient clinics ( $\bullet$ Table2).

During the period 2013/2014, the correlation between adjusted ADRs and adjusted complication rates amounted to $\mathrm{R}=0.24(P<$ 0.01 ; see $\bigcirc$ Fig. 5), and between adjusted ADRs and adjusted PLDRs it was $\mathrm{R}=0.85(P<0.01$; see $\bullet$ Fig. 6$)$.

\section{Complications}

Complications occurred in $0.2 \%$ of all colonoscopies performed $(\mathrm{n}=361)$. The most common complication was bleeding $(\mathrm{n}=165$, $0.1 \%$ of all colonoscopies) followed by cardiopulmonary events $(n=134,0.08 \%)$ and others $(n=42,0.03 \%)$. Perforation occurred in $0.01 \%$ of all colonoscopies $(n=20)$. In 341 cases with complications, patients reached a restitutio ad integrum (no consequential damage), one adverse event (a perforation) caused secondary damage, and 19 outcomes were unknown. There were no fatal outcomes reported in the screening cohort. Most $(63.4 \%, n=$ 229 ) of the complications occurred in colonoscopies in which polypectomy had been performed: $94.6 \%(n=156)$ of bleedings, $31.3 \%(n=42)$ of cardiopulmonary events, $55.0 \%(n=11)$ of perforations, and $47.6 \%(n=20)$ of other complications. About a third of complications (30.2\%, $\mathrm{n}=109$ ) occurred in colonoscopies with no pathological findings, $1.4 \%(n=5)$ in colonoscopies with at least one polyp detected but not resected, and $4.2 \%(n=15)$ in colonoscopies with pathological findings other than polyps.

Sedation increased the probability of complications. Adverse events occurred in $0.24 \%$ ( $95 \% \mathrm{CI} 0.21 \%-0.26 \%$ ) of colonoscopies in which sedation was administered and in $0.16 \%$ (95\%CI $0.11 \%-$ $0.22 \%)$ of procedures without sedation $(P=0.03$; relative risk $1.51,95 \%$ CI $1.05-2.17)$. Notably, all perforations occurred in sedated patients; the perforation rate was $0.01 \%$ in sedated patients $(20 / 138845 ; P=0.17)$.

\section{Data quality}

Verification of the electronic documentation of data had been performed since 2011 ( Table 3 ). The majority of participants ( $82 \%$ in $2011,89 \%$ in $2012,94 \%$ in $2013,88 \%$ in 2014 ) had entered the correct data in the reports that were randomly selected for verification. Those with incorrect or missing data in the firstline verification had correct data in the second-line verification ( $3 \%$ in $2011,8 \%$ in $2012,4 \%$ in 2013 , $3 \%$ in 2014 ) or were excluded from continuing in the quality assurance program for other reasons ( $11 \%$ in $2011,3 \%$ in $2012,2 \%$ in $2013,0 \%$ in 2014 ).

To date, no endoscopist had to be excluded from the quality assurance project because of incorrect data entry.
Table 2 Break down of participating endoscopists who did not meet quality standards.

\begin{tabular}{|c|c|c|c|c|}
\hline & \multicolumn{4}{|l|}{ Period } \\
\hline & 2007| & 2009| & 2011/ & 2013/ \\
\hline & 2008 & 2010 & 2012 & 2014 \\
\hline ADR $<20 \%, n(\%)$ & $45(42.5)$ & $99(55.6)$ & $85(42.1)$ & $79(35.0)$ \\
\hline Private practices & 34 (47.9) & $69(61.1)$ & $72(46.8)$ & $65(37.4)$ \\
\hline $\begin{array}{l}\text { Hospitals/outpatient } \\
\text { clinics }\end{array}$ & $11(31.4)$ & $30(46.2)$ & $13(27.1)$ & $14(26.9)$ \\
\hline CIR $<90 \%, n(\%)$ & $16(15.1)$ & $20(11.2)$ & 20 (9.9) & $16(7.1)$ \\
\hline Private practices & $13(18.3)$ & $18(15.9)$ & $18(11.7)$ & $13(7.5)$ \\
\hline $\begin{array}{l}\text { Hospitals/outpatient } \\
\text { clinics }\end{array}$ & $3(9)$ & $2(3)$ & $2(4)$ & $3(6)$ \\
\hline
\end{tabular}

$\mathrm{ADR}$, adenoma detection rate; CIR, cecal intubation rate.

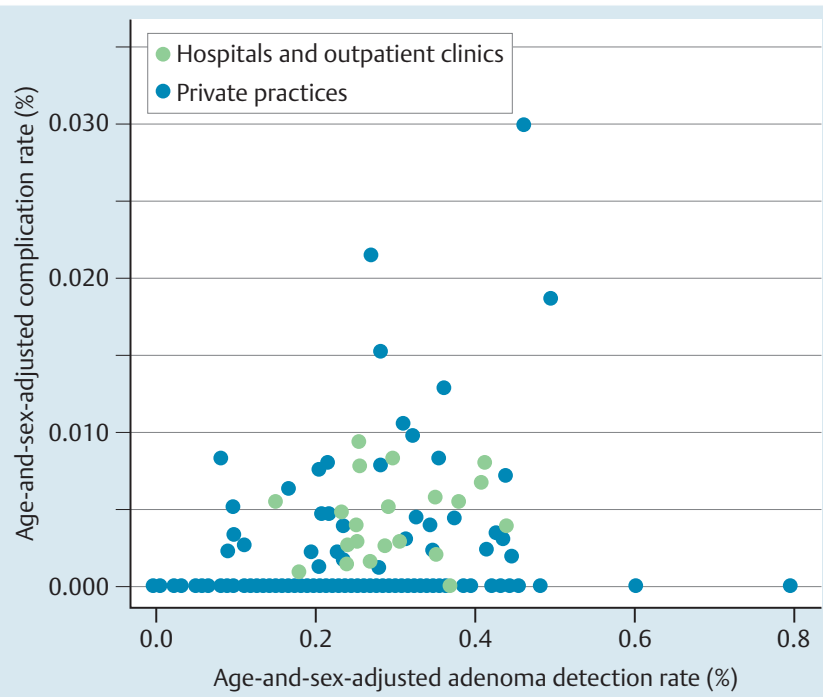

Fig. 5 Correlation of age- and sex-adjusted complication rate and ageand sex-adjusted adenoma detection rate of endoscopists who participated in 2013/2014.

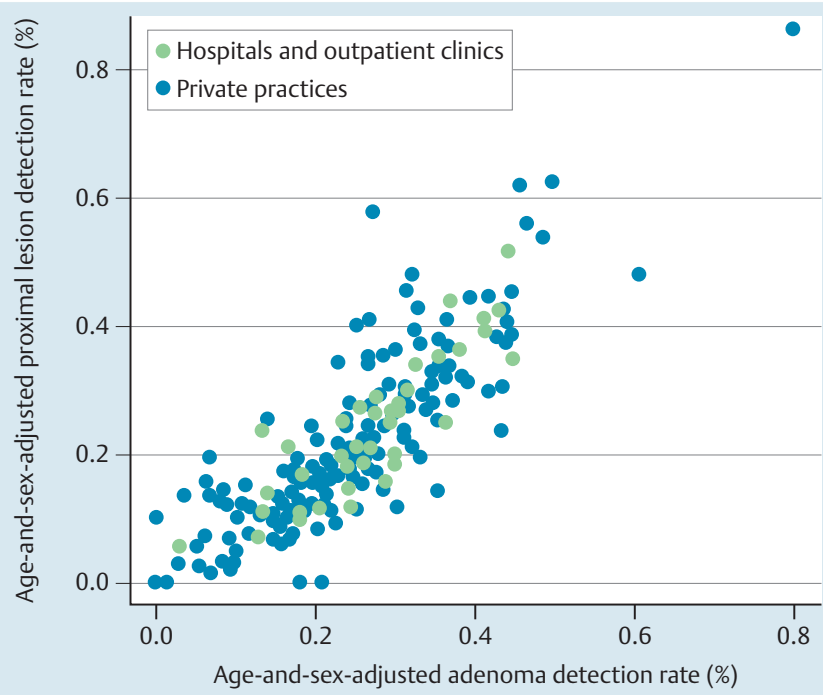

Fig. 6 Correlation of age- and sex-adjusted proximal lesion detection rate and age- and sex-adjusted adenoma detection rate of endoscopists who participated in 2013/2014. 


\begin{tabular}{|c|c|c|c|c|}
\hline & $2011(n=219)$ & $2012(n=207)$ & $2013(n=220)$ & $2014(n=220)$ \\
\hline No random sample test, \% participating endoscopists & $14(n=30)$ & $8(n=16)$ & $14(n=30)$ & $2(n=5)$ \\
\hline New participation toward the end of the year, \% & 10 & 31 & 3 & 80 \\
\hline Too few endoscopy reports submitted, \% & 90 & 38 & 37 & - \\
\hline No electronic data submission, \% & - & - & 17 & - \\
\hline Exclusion, \% & - & 31 & 43 & 20 \\
\hline Random sample test, \% participating endoscopists & $86(n=189)$ & $92(n=191)$ & $86(n=190)$ & $98(n=215)$ \\
\hline Correct data entry, \% & 81 & 89 & 94 & 88 \\
\hline Correct data entry in the second run, \% & 3 & 8 & 4 & 3 \\
\hline Exclusion, \% & 13 & 3 & 2 & - \\
\hline $\begin{array}{l}\text { No documentation/data missing by the time of creation } \\
\text { of the manuscript, \% }\end{array}$ & 3 & - & - & 9 \\
\hline Reasons for negative random sample test & $\begin{array}{l}\text { Not reported for this } \\
\text { year }\end{array}$ & $(n=15)$ & $(n=8)$ & $(n=7)$ \\
\hline Incorrect classification of the detected lesion, \% & & 13 & 50 & 57 \\
\hline Incorrect indication of size, \% & & 40 & 12.5 & - \\
\hline Incorrect count of polyps, \% & & 7 & - & 29 \\
\hline Incorrect patient records, \% & & 13 & - & - \\
\hline Unknown, \% & & 27 & - & - \\
\hline Record form lost, \% & & - & 25 & - \\
\hline $\begin{array}{l}\text { Missing photographic documentation of the cecum/ } \\
\text { cecum not reached, \% }\end{array}$ & & - & 12.5 & 14 \\
\hline
\end{tabular}

\section{Hygiene control}

In 2010, hygiene controls of endoscopic equipment used by 89 participants were required. In $7.9 \%(n=7)$ of cases, pathological germs were detected and the participants provided a second, germ-free result after eradication. In 2011, 98 private practices were certified, and $5.1 \%(n=5)$ had positive test result. This was a decrease of $2.8 \%$ compared with 2010. In 2012, 5.0\% $(n=6)$ of 120 participants had contaminated instruments, which was again a decrease of $0.1 \%$ compared with 2011. In 2013, 8.1\% ( $n=$ 10) of 123 showed contamination, which was an increase of $3.1 \%$ compared with 2012 ; in $2014,6.0 \%(n=8)$ of 133 , a decrease of $2.1 \%$ compared with 2013 and a decrease of $1.9 \%$ compared with 2010. In 2012 and 2013, 100\% of germs were Pseudomonas spp.; in 2014, $87.5 \%$ were Pseudomonas spp.and $12.5 \%$ were Sphingomonas spp.

\section{Discussion \\ $\nabla$}

Screening colonoscopy in Austria performed within the quality assurance project described in this paper meets international standards in terms of both premalignant lesion detection rates and safety standards. Age- and sex-adjusted ADR significantly increased during the study period investigated from $22.2 \%$ to $24.2 \%$, corresponding to an average increase of +1.5 percentage points per 2-year period for an average endoscopist. In addition, the detection rate of proximal lesions increased from $15.8 \%$ to $21.7 \%$. Overall, $95.5 \%$ of polyps were resected, and $97.3 \%$ of the retrieved polyps were sent for histopathological evaluation, which meets the requirement of 95\% [6]. Perforations occurred in 1:7962 colonoscopies and 1:7225 colonoscopies with polypectomy. Bleedings occurred in 1:521 colonoscopies with polypectomy. Possible reasons for higher complication rates in procedures with sedation are a reduced perception of pain by patients and subsequent failure of the endoscopist to notice alert signals.
Regarding data quality, the percentage of correct data entry increased by 13 percentage points in the first 3 years after implementation of the quality assurance project, and was $94 \%$ in 2013. However, changes in the report form led to a deterioration in quality of data transmission. After the extension of the report form in 2013, which involved the inclusion of number of adenomas, resection technique (cold/high-frequency snare resection), and differentiation between screening and surveillance colonoscopy, the percentage of correct data entry decreased by $6 \%$.

The percentages of contaminated endoscopes and washing machines were low. Overall, the rate of contaminated equipment decreased by $1.9 \%$. Interestingly, in 2013, a year when many private practices joined the quality assurance project, the proportion of contaminated instruments increased by $3.1 \%$; the following years, this rate was falling again.

The awareness of endoscopic CRC prevention in Austria compared with the EU average is relatively high [18]. Past experiences have not only emphasized the importance of application of quality criteria, but also of monitoring via an independent structure in order to reveal deficiencies and provide options for intervention in an adequate and effective manner. In 2004, a report was published that revealed poor performance in screening colonoscopy in the United Kingdom, which was attributed to inadequate training [19]. The cecum was reached in less than $80 \%$, every fifth examination was performed with poor bowel preparation, only half of the patients recalled that they had been informed about possible adverse events before the procedure, and perforation occurred in 1:769 procedures [19]. As a consequence, public funding was provided to improve colonoscopy performance, not only by practical training, but also by the introduction of an Endoscopy Global Rating Score, a web-based self-assessment tool for use in endoscopy units [20], and a National Bowel Cancer Screening Program, which implemented quality standards and an accreditation test for participation [21]. As a result, an improvement in quality was demonstrated in 2013 [22]; for example, the adjusted CIR increased from $76.9 \%$ to $95.8 \%$ [19,22]. In the 
present study, ADR and PDR increased in 2013/2014 compared with $2007 / 2008$ by +2 percentage points and +5.3 percentage points, respectively. Unadjusted CIR increased by 2.8 percentage points.

A large study from Poland identified the gold standard of an ADR of $\geq 20 \%$ in screening colonoscopy. The authors showed that an ADR of $\geq 20 \%$ significantly decreased the risk for interval cancers, which are cancers that developed between a screening colonoscopy and the scheduled time of surveillance colonoscopy [8]. Data from Austria confirmed that required ADR standards of $\geq 20 \%$ [9] are met (currently $24.2 \%$ ) and stressed the need for sex-specific screening recommendations [11]. In US studies, a target ADR of $>15 \%$ in women and $>25 \%$ in men was proposed [5]. Recently, even higher ADR standards of $\geq 20 \%$ for women and $\geq 30 \%$ for men have been suggested $[10,23]$. However, compared with most European studies, US guidelines are based on data from specialized centers and therefore applicability for outpatient clinics and office-based physicians is debatable.

A German study group recently published a study on trends in screening colonoscopy. Brenner et al. reported an increase in ADR (nonadvanced adenoma detection rate increased from $13.3 \%$ to $22.3 \%$ in men and from $8.4 \%$ to $14.9 \%$ in women) in a study population of 4.4 million patients between 2003 and 2012. Age-adjusted CIR was $>98 \%$ in 2003 and changed little during the study period investigated. Age-adjusted bleeding and perforation rates were $0.5 \%$ and $0.1 \%$, respectively. The authors argued that the increase in ADRs results, at least partly, from an innovation effect [24]. The present study cohort also showed an increase in ADR (average +1.5 percentage points per 2 -years period overall, +1.6 percentage points in men, and +1.9 percentage points in women), as well as PDR (36.7\% to $42.0 \%)$. Notably, also CIR increased significantly (from $94.2 \%$ to $97.0 \%$ ). The positive effect of specific interventions on ADRs has been reported in several studies $[25,26]$. Therefore, if studies on new benchmark requirement and/or new guidelines on screening are published, these publications are communicated to participating endoscopists by information letters. However, the positive trend in ADR in the present study might have resulted from many factors, such as: increasing awareness about the importance of ADR not related to the quality assurance program; possible changes in training and experience of participating endoscopists; possible changes in equipment and bowel preparation; differences in performance of incoming, leaving and continuing endoscopists; and trends in demographics and risk of screening participants. Constant audit and feedback in the form of benchmarking has certainly contributed to the strong increase in ADR in the present study population. In order to assess the amount of this increase that can be attributed to the quality assurance interventions, a comparison with endoscopies performed outside of the screening program is inevitable. However, like most other countries, in Austria there is no obligatory quality control program and therefore no universal assessment of ADR or other metrics. In order to make general statements on the trends in ADR and other quality parameters from a nationwide perspective, provision of colonoscopy reports and their assessment by an independent authority are mandatory, which underlines the strong need for respective guidelines comparable to the Germen model [24].

Another interesting finding was that although the ADR significantly increased over the investigated time period, the AADR decreased. AADR is known to be associated with sex and age $[8,11]$. However, AADR in the present study cohort was presented separately for men and women (both decreased) and adjusted for age; age did not differentiate between the investigated time periods. Notably, there was wide variation in the detection of advanced adenomas as a proportion of all adenomas detected per endoscopists (median 25.6\%, interquartile range $16.7 \%-38.3 \%$ ). Big differences in the percentage of individuals with advanced adenomas have been noted in other average-risk populations [27]. A possible explanation for the negative trend might lie in potential overdiagnosis of advanced adenomas in the earlier certification periods; overdiagnosis might have been due to the definition of advanced adenomas - a combination of a clinical (size, estimated by the endoscopist) and histopathological (amount of villous component, set by the pathologist) diagnosis - rather than higher prevalence rates. It has been shown that endoscopists tend to overestimate the size of a lesion [28], which in combination with a villous histology of an adenoma leads to overdiagnosis of advanced adenomas. Moreover, to our knowledge there are no data on the accuracy of the diagnosis of a villous adenoma made by pathologists, which has major impact on the AADR.

To date, approximately half of all endoscopy units in Austria participate voluntarily in the quality assurance project, which is an encouraging result. However, efforts to ensure more comprehensive coverage in the future are required, for example, by making participation in the quality assurance project a condition of participation in the national screening program, and providing appropriate financial reward for endoscopists. However, the implementation of the present quality assurance project was a milestone towards comprehensive assessment and objective demonstration of trends in adenoma, advanced adenoma, and polyp detection rates. The acquired database provides the unique opportunity to analyze trends in effectiveness of screening colonoscopy, which impacts on patient benefit and safety as well as cost-effectiveness. Therefore, publication of these data is expected to give an important impulse to negotiations in this matter.

Limitations of this study include participation in the quality assurance project, which was on a voluntary basis; even though participation shows interest in and willingness to improve individual performance, it constitutes a possible bias by including particularly well trained endoscopists with above-average performance. A further limitation is the method of determining accuracy of the data captured in the database. Three randomly selected colonoscopy reports per endoscopist per year might be an insufficient number to monitor such a large data transfer. In the current form, the probability of missing incorrect data is rather high. However, the current personal and financial resources permit only this small sample test to be performed. Therefore, a future goal of the project is to acquire more resources in order to improve this very important issue. In addition, we did not assess colonoscope withdrawal time, which should be at least 6 minutes in screening colonoscopy [29]. However, inclusion of withdrawal time into the report form is a future goal of the project. Another limitation, which applies to most quality record forms, is the lack of assessment of patient comfort, despite this measure being recommended as an auditable outcome in screening colonoscopy in the EU guidelines [30]. In addition, complications are assessed solely in the electronic report form; there is no long-term followup (e.g. contacting patients after 30 days). Finally, although participants are obliged contractually to provide reports of all screening colonoscopies performed (provided the screened individuals have given written informed consent), and the count of screening colonoscopy is assessed twice a year in the benchmark reports, a certain selection bias cannot be excluded with absolute certainty. 
In summary, screening colonoscopy in the present study cohort revealed high quality standards and showed positive trends during the investigated study period. Detection rates of adenomas, advanced adenomas, and proximal lesions in both men and women increased significantly during the study period, whereas AADR decreased.

\section{Competing interests: None.}

\section{Institutions}

${ }^{1}$ Department of Internal Medicine III, Division of Gastroenterology and

Hepatology, Medical University of Vienna, Vienna, Austria

${ }^{2}$ Austrian Society of Gastroenterology and Hepatology (OEGGH) Quality assurance Working Group, Vienna, Austria

${ }^{3}$ Center for Medical Statistics, Informatics and Intelligent Systems, Section for Clinical Biometrics, Medical University of Vienna, Vienna, Austria

${ }^{4}$ Main Association of the Austrian Social Insurance Institutions, Vienna, Austria

\section{Acknowledgments}

We thank S. Pramhas, C. Wiener, C. Reinhart, C. Bannert, O. Gal, and P. Salzl for their input in implementation of the certificate. We also thank W. Vogel, P. Knoflach, and W. Petritsch for their thoughtful support in the project. The Austrian Society for Gastroenterology and Hepatology, the Main Association of the Austrian Social Insurance Institutions, and the Austrian Cancer Aid, particularly D. Kiefhaber and J. Probst, supported and founded the quality assurance project. In particular, we thank all endoscopists who participate and have formerly participated at the "quality certificate for colorectal cancer prevention" for the excellent cooperation and data contribution. A list of current participants is available at http:// www.vorsorgekoloskopie.at. Finally, we thank everyone who supported the quality certificate for screening colonoscopy, and generally, projects on CRC awareness and prevention.

The project "Quality Certificate for Screening Colonoscopy" was established in cooperation with the Main Association of the Austrian Social Security Institution and supported by fund $\S 447 \mathrm{~h}$ ASVG (Fund for preventive check-ups and health promotion), the Austrian Cancer Aid and the Austrian Society of Gastroenterology and Hepatology.

\section{References}

1 Zauber AG, Winawer SJ, O'Brien MJ et al. Colonoscopic polypectomy and long-term prevention of colorectal-cancer deaths. N Engl J Med 2012; 366: 687-696

2 Winawer SJ, Zauber AG, Ho MN et al. Prevention of colorectal cancer by colonoscopic polypectomy. The National Polyp Study Workgroup. N Engl J Med 1993; 329: 1977-1981

3 Altobelli E, Lattanzi A, Paduano R et al. Colorectal cancer prevention in Europe: burden of disease and status of screening programs. Prev Med 2014; 62: $132-141$

4 Jover $R$, Herraiz $M$, Alarcon $O$ et al. Clinical practice guidelines: quality of colonoscopy in colorectal cancer screening. Endoscopy 2012; 44: $444-451$

5 Rex DK, Petrini JL, Baron TH et al. Quality indicators for colonoscopy. Gastrointest Endosc 2006; 63: 16-28

6 Rex DK, Bond JH, Winawer $S$ et al. Quality in the technical performance of colonoscopy and the continuous quality improvement process for colonoscopy: recommendations of the U.S. Multi-Society Task Force on Colorectal Cancer. Am J Gastroentoerl 2002; 97: 1296-1308

7 Segnan N, Patnick J, von Karsa $L$ et al. European guidelines for quality assurance in colorectal cancer screening and diagnosis - first edition. Luxembourg: Publications Office of the European Union. 2010: Available at: http://www.kolorektum.cz/res/file/guidelines/CRC-screeningguidelines-EC-2011-02-03.pdf Accessed: 11 July 2016

8 Regula J, Rupinski M, Kraszewska E et al. Colonoscopy in colorectal-cancer screening for detection of advanced neoplasia. N Engl J Med 2006; 355: $1863-1872$
9 Kaminski MF, Regula J, Kraszewska E et al. Quality indicators for colonoscopy and the risk of interval cancer. N Engl J Med 2010; 362: $1795-1803$

10 Corley $D A$, Jensen $C D$, Marks $A R$ et al. Adenoma detection rate and risk of colorectal cancer and death. N Engl J Med 2014; 370: 1298-1306

11 Ferlitsch M, Reinhart K, Pramhas $S$ et al. Sex-specific prevalence of adenomas, advanced adenomas, and colorectal cancer in individuals undergoing screening colonoscopy. JAMA 2011; 306: 1352-1358

12 Bannert C, Reinhart K, Dunkler D et al. Sedation in screening colonoscopy: impact on quality indicators and complications. Am J Gastroenterol 2012; 107: 1837 - 1848

13 Reinhart K, Bannert C, Dunkler D et al. Prevalence of flat lesions in a large screening population and their role in colonoscopy quality improvement. Endoscopy 2013; 45: $350-356$

14 Waldmann E, Britto-Arias M, Gessl I et al. Endoscopists with low adenoma detection rates benefit from high-definition endoscopy. Surg Endosc 2015; 29: 466-473

15 Ferlitsch M, Heinze G, Salzl P et al. Sex is a stronger predictor of colorectal adenoma and advanced adenoma than fecal occult blood test. Med Oncol 2014; 31: 151

16 Jeschek P, Ferlitsch A, Salzl P et al. A greater proportion of liver transplant candidates have colorectal neoplasia than in the healthy screening population. Clin Gastroenterol Hepatol 2015; 13: 956-962

17 Kozbial K, Reinhart K, Heinze G et al. High quality of screening colonoscopy in Austria is not dependent on endoscopist specialty or setting. Endoscopy 2015; 47: 207-216

18 Stock C, Brenner $H$. Utilization of lower gastrointestinal endoscopy and fecal occult blood test in 11 European countries: evidence from the Survey of Health, Aging and Retirement in Europe (SHARE). Endoscopy 2010; 42: 546- 556

19 Bowles CJ, Leicester R, Romaya C et al. A prospective study of colonoscopy practice in the UK today: are we adequately prepared for national colorectal cancer screening tomorrow? Gut 2004; 53: 277-283

20 British Society of Gastroenterology. Endoscopy Global rating Scale. Available from: http://www.bsg.org.uk/clinical-guidance/endoscopy/ endoscopy-global-rating-scale.html Accessed 11 July 2016

21 Chilton A, Rutter M. Quality assurance guidelines for colonoscopy. Sheffield: NHS Cancer Screening Programmes. 2011: Available at: https:/ www.gov.uk/government/uploads/system/uploads/attachment_data/ file/427591/nhsbcsp06.pdf Accessed: 11 July 2016

22 Gavin DR, Valori RM, Anderson JT et al. The national colonoscopy audit: a nationwide assessment of the quality and safety of colonoscopy in the UK. Gut 2013; 62: $242-249$

23 Rex DK, Schoenfeld PS, Cohen J et al. Quality indicators for colonoscopy. Gastrointest Endosc 2015; 81: 31-53

24 Brenner H, Altenhofen L, Kretschmann J et al. Trends in adenoma detection rates during the first 10 years of the German Screening Colonocopy Program. Gastroenterology 2015; 149: 356-366

25 Kahi CJ, Ballard D, Shah AS et al. Impact of a quarterly report card on colonoscopy quality measures. Gastrointest Endosc 2013; 77: 925 931

26 Coe SG, Crook JE, Diehl NN et al. An endoscopic quality improvement program improves detection of colorectal adenomas. Am J Gastroenterol 2013; 108: 219-226

27 Pox CP, Altenhofen L, Brenner $H$ et al. Efficacy of a nationwide screening colonoscopy program for colorectal cancer. Gastroenterology 2012; 142: $1460-1467$

28 Anderson BW, Smyrk TC, Anderson KS et al. Endoscopic overestimation of colorectal polyp size. Gastrointest Endoc 2016; 83: 201 -208

29 Barclay RL, Vicari JJ, Doughty AS et al. Colonoscopic withdrawal times and adenoma detection during screening colonoscopy. N Engl J Med 2006; 355: 2533-2541

30 European Colorectal Cancer Screening Guidelines Working Group. von Karsa L, Patnick $J$ et al. European guidelines for quality assurance in colorectal cancer screening and diagnosis: overview and introduction to the full supplement publication. Endoscopy 2013; 45: 51 - 59

\section{Correction}

Elisabeth Waldmann, Irina GessI, Daniela Sallinger et al. Trends in quality of screening colonoscopy in Austria. Endoscopy 2016, 48: 1102-1109

Figs. 5 and 6: the graphs in these figures were inadvertently transposed in the e-first publication. This has now been corrected. 